\title{
Structure and Mechanical Properties of Polymeric Composites with Carbon Nanotubes
}

\author{
K. Gusev \\ Department of Physics, Faculty of \\ Physics and Mathematics, Pskov State \\ University, \\ Lenin Square 2, 180000 Pskov, Russia \\ V. Solovyev \\ Department of Physics, Faculty of \\ Physics and Mathematics, Pskov State \\ University, \\ Lenin Square 2, 180000 Pskov, Russia
}

\author{
V. Gerbreders \\ G. Liberts'Innovative Microscopy \\ Centre, Daugavpils University, \\ Vienibas Street 13,LV-5400 Daugavpils,
} Latvia

\author{
A. Ogurcovs \\ G. Liberts'Innovative Microscopy \\ Centre, Daugavpils University,
}

Vienibas Street 13,LV-5400 Daugavpils,

Latvia

\begin{abstract}
Experimental investigations of single-wall carbon nanotubes (CNT) effect on the mechanical properties of polymeric composite materials based on epoxy matrix have been carried out. It has been found that addition of CNT at low concentration dramatically increases tensile strength (20 - 30 per cent growth) and Young's modulus of the samples under study.

Structure of polymeric composites with CNT was characterized by atomic force microscopy (AFM) and scanning electron microscopy (SEM). AFM images of the samples under study confirm strong interaction between polymeric matrix and nano-additives, demonstrating intimate contact between CNT and epoxy surroundings which is of great importance for composite material reinforcement.

Dependences of tensile strength and those of Young's modulus on CNT concentration are discussed using micromechanics models for nanocomposites.
\end{abstract}

Keywords - polymeric composites, carbon nanotubes, mechanical properties.

\section{INTRODUCTION}

Due to the high values of tensile strength and Young's modulus combined with the large aspect ratio and giant surface area single wall carbon nanotubes (CNT) with small weight fraction are shown to be the most promising nanoparticle fillers for improving mechanical properties of polymeric composites widely using in many industries [1-4].

Different energy dissipating and thus tensile strength increasing mechanisms at the CNT have been proposed. Among these mechanisms are nanotube pull-out, nanoparticle-matrix debonding and nanotube breakage [3]. In particular, the bonds between the CNTs and polymer chains enable a stress transfer between the host matrix (polymer) and guest substance (CNTs). This mechanism decreases the rate of crack formation, redirects cracks and restricts the mobility of the main chain of the epoxy resin leading to an increase of the Young's modulus [4].

On the other hand, researchers used multiwalled CNTs in order to improve the interfacial properties between carbon fibers and epoxy matrix in multicomponent composite materials [5]. In this case, it was concluded that the Van der Waals force combination and the mechanical interlock increase the internal friction of carbon fiber - epoxy matrix and limit the movement of the interface of the composite, which plays an important role in the enhancement of interface interaction.

It should be emphasized that in general, the level of interaction between matrix and fillers ("nanoadhesion") [6 - 8] is of great importance for composite material reinforcement.

In this work, mechanical properties of epoxybased multicomponent composite material containing glass fibers and single-wall CNT nano-additives have been studied. Structural investigations of CNT / epoxy composite under study confirm strong interaction between host matrix and guest substance, demonstrating intimate contact between CNT and epoxy surroundings which is of great importance for composite material reinforcement (noticeable growth of tensile strength and Young's modulus of composite material when compared with check sample without adding CNTs).

\section{Materials and Methods}

We prepared CNT / epoxy nanocomposite based on ED-20 epoxy resin, hardener and concentrate (paste) TUBALL MATRIX from OCSiAL (Novosibirsk, Russia), containing single wall carbon nanotubes (CNT) with a length $L>5$ microns and diameter $d=(1.6 \pm 0.4) \mathrm{nm}$. The technology of composite materials preparation included the following stages:

1. Weighing the estimated amount of the paste TUBALL MATRIX containing 10 mass. \% CNT, on AXIS A6N 200 analytical balance.

2. Weighing the calculated amount of epoxy resin.

3. Hand mixing of the compound with the help of a stirrer in order to prevent the accumulation of concentrate (to obtain positive results, mixing of 
the binder was carried out in a cylindrical vessel with a flat bottom).

4. Mixing with a suspended mechanical mixer (2000 rpm for 20 minutes).

5. Quality control of the resulting mixture using a glass rod. The mixture was distributed in a thin layer on a white sheet of paper. If the "smear" was homogeneous, without signs of roughness, the mixture was considered prepared for the introduction of the hardener. Otherwise, the stirring was continued.

6. Adding the calculated amount of hardener immediately after mixing in order to polymerize the compound as soon as possible and prevent CNT agglomeration.

Finally, cylindrical rods with a diameter $d=(10 \pm 1) \mathrm{m}$ containing CNT / epoxy and glass fibers with a diameter of $24 \mu \mathrm{m}$ and concentration 85 vol. \%

were fabricated at the "Polycomposite" firm (Pskov, Russia). Experimental study of mechanical characteristics of the samples has been carried out in the laboratory of this firm branch using the universal testing machine H300KU-0050 «Tinius Olsen Ltd».

Structure of nanocomposites under study was characterized by «VEGA // LMU Tescan» Scanning Electronic Microscope (SEM, see Fig. 1) and "PARK NX10" atomic force microscope (AFM, see Fig. 2).

\section{Results AND Discussion}

During this work, 7 types of compounds with TUBALL MATRIX paste and a check sample (without adding CNT) were prepared.

The results of the experimental study of physical and mechanical characteristics of the samples obtained using the universal testing machine H300KU-0050 "Tinius Olsen Ltd" are given in table 1.

TABLE I

PHYSICAL AND MECHANICAL CHARACTERISTICS OF POLYMERIC COMPOSITES

\begin{tabular}{|c|c|c|c|c|}
\hline Sample number & Paste type & Mass CNT concentration $\mathrm{W}_{\mathrm{CNT}} \%$ & Tensile strength $\sigma, \mathrm{MPa}$ & Young's modulus $E, \mathrm{GPa}$ \\
\hline Glass fibers & - & - & 1970 & 78.8 \\
\hline Check composite sample & - & 0 & 1103 & 51.6 \\
\hline 1 & MATRIX 301 & 0.04 & 1456.0 & 54.2 \\
\hline 2 & MATRIX 301 & 0.08 & 1412.0 & 53.9 \\
\hline 3 & MATRIX 301 & 0.02 & 1333.0 & 53.5 \\
\hline 4 & $\begin{array}{c}\text { MATRIX PD } \\
0072\end{array}$ & 0.04 & 1380.0 & 53.6 \\
\hline 5 & $\begin{array}{c}\text { MATRIX PD } \\
0072 \\
\end{array}$ & 0.08 & 1252.5 & 52.4 \\
\hline 6 & $\begin{array}{c}\text { MATRIX PD } \\
0073\end{array}$ & 0.04 & 1445.0 & 53.8 \\
\hline 7 & $\begin{array}{l}\text { MATRIX PD } \\
0073\end{array}$ & 0.08 & 1300.0 & 54.8 \\
\hline
\end{tabular}

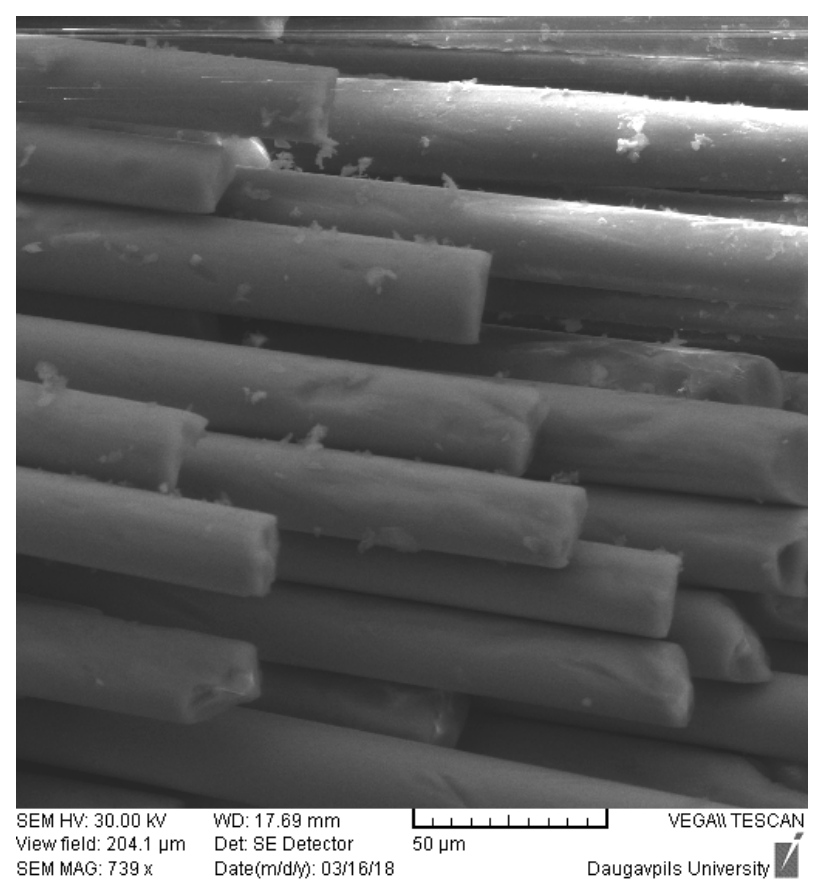

Fig. 1. SEM image of the glass fibers arrangement in epoxybased nanocomposite containing carbon nanotubes.

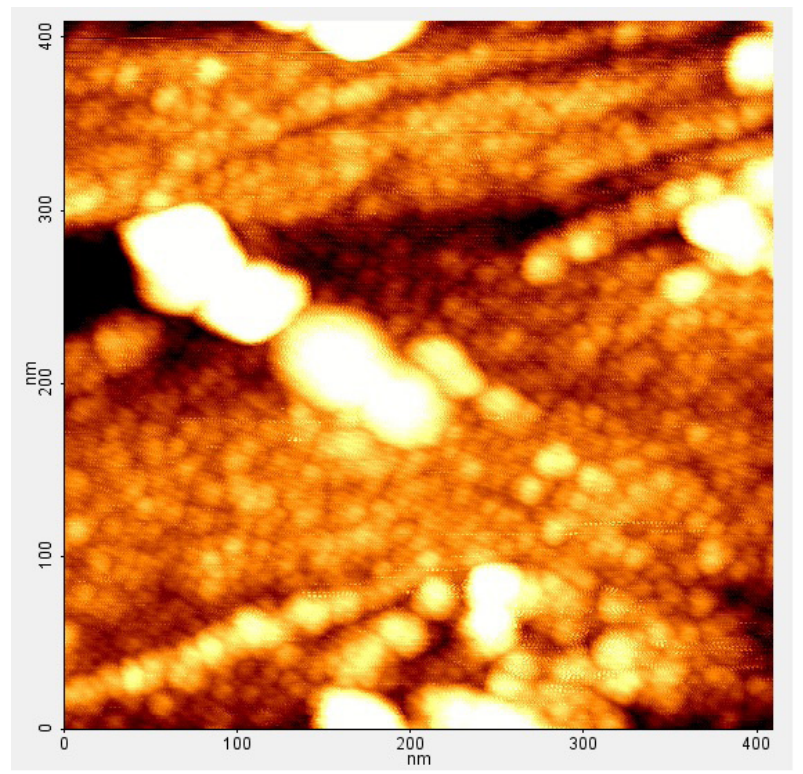

Fig. 2. AFM image of CNT interacting with polymeric matrix in CNT / epoxy composite.

One can consider these experimental results taking into account classical Kelly and Tyson theory [9, 10] which predicts the tensile properties of a fiber-reinforced material from the mechanical properties of fiber and 
matrix. According to this theory, when very strong continuous fibers with volume fraction $V_{f}$ are embedded in a matrix which has a yield stress for plastic flow very much less than the breaking stress of the fibers, the tensile strains in fiber and matrix are taken to be equal and we have

$$
\sigma_{c}=\sigma_{f} V_{f}+\sigma_{m}\left(1-V_{f}\right),
$$

where $\sigma_{c}, \sigma_{f}, \sigma_{m}$ are the values of the tensile strength of composite, fiber, and matrix, respectively.

Similarly, in the elastic range one can write:

$$
E_{c}=E_{f} V_{f}+E_{m}\left(1-V_{f}\right),
$$

where $E_{c}, E_{f}, E_{m}$ are the values of the Young's modulus (modulus of elasticity) of composite, fiber, and matrix, respectively.

Taking into consideration that in our case

$$
\sigma_{f}>\sigma_{m} \text { and } E_{f}>E_{m} \text {, one can obtain: }
$$

$$
\sigma_{c} \approx \sigma_{f} V_{f} \quad \text { (3) and } E_{c} \approx E_{f} V_{f} \text {. }
$$

Thus, we can estimate expectative values of $\sigma_{c} \approx 1680 \mathrm{MPa}$ and $\quad E_{c} \approx 67 G P a$ for $E_{f} \approx 85$ $\sigma_{f} \approx 1970 \mathrm{MPa}$ and $E_{f} \approx 78.8 G P a$.

As can be seen from table 1, corresponding experimental values for the check composite sample (without nanotubes) are much less than these ideal theoretical predictions. However, after addition of CNTs into epoxy matrix (which has to bear stress when the strain of the composite is such that the fibers are strained to their ultimate tensile strain [9]) the deviation of experimental results from theoretical limits becomes much smaller (for the tensile strength this deviation can drop from $50 \%$ to $15 \%)$. Thus, addition of carbon nanotubes strengthens matrix under stress, therefore this matrix becomes strong enough to provide adequate load transfer to the glass fibers.

For CNT-reinforcement of composite material the applied load must be transferred from polymer to nanotubes by means of shear forces at the nanotube / epoxy interface. Hence, matrix has to bear rather high tangential strength without breakdown. One can suppose that addition of CNT enhances both normal and tangential components of matrix limit mechanical stress. In order to propose micromechanical mechanism of this effect one can estimate a CNT critical length [9-12]:

$$
L_{c}=\frac{\sigma_{C N T} d}{2 \tau},
$$

where $d=(1.6 \pm 0.4) n m-\mathrm{CNT}$ diameter for the samples under study, $\sigma_{C N T} \approx 37 G P a-$ mean value for CNT tensile strength and $\tau \approx 10 M P a$ - typical value for interfacial shear strength in CNT / polymer nanocomposites [11]. Substituting these values into formula (5) one obtains $L_{c} \approx 3 \mu \mathrm{m}<L$. Thus, in our CNT / epoxy nanocomposite the length of nanotubes exceeds the critical value; hence, the epoxy matrix is able to load
CNTs to their fracture stress (at $L<L_{c}$ the CNT is pulled out of matrix before its failure [10]).

Fig. 2 demonstrates some interesting characteristic features of the interaction between nanotubes and polymeric matrix in $\mathrm{CNT}$ / epoxy composite. One can see that CNTs in epoxy matrix are not similar to the freely moving "hair in pie"; due to the strong CNT - epoxy interaction, spherical polymeric nanoparticles on the nanotube look like the beads on the thread. In our opinion, this type of mechanical interaction between modified corrugated (covered with polymeric "nanoballs") CNTs and host epoxy matrix within composite material is analogous to the behavior of corrugated armature in reinforced concrete.

It should be noted that increasing the filler concentration leads to the significant reduction of mechanical characteristics of composite material due to the agglomeration of the additives $[6,7,13]$. This tendency can be clearly seen from Fig. 3, demonstrating concentration dependence of the Young's modulus enhancement effect in the nanocomposite under study. The graph shows that at low concentrations of CNTs $\mathrm{W}_{C N T}<0.04 \mathrm{wt} . \%$ one can approximate experimental data by theoretically expected [14] dependence

$$
\frac{E_{c}}{E_{0}}=1+A \cdot W_{C N T}^{0.5},
$$

but afterwards the Young's modulus of the nanocomposite $\left(E_{c}\right)$ begins to decrease with increasing CNT concentration probably due to the beginning of the agglomeration process.

Tensile strength of the nanocomposites under study demonstrates the similar behavior (see table 1).

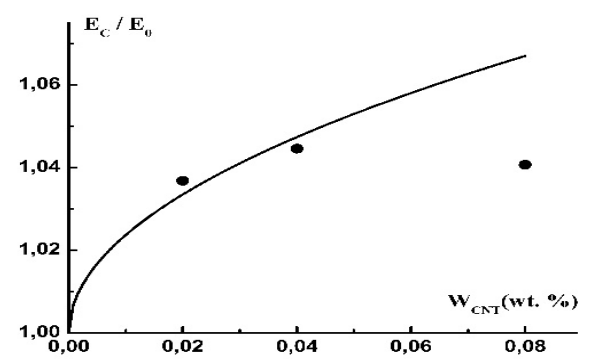

Fig. 3. Ratio of the mean value of the Young's modulus of the nanocomposite, $E_{c}$ to that of the check composite sample (without

CNTs), $E_{0}$ versus CNT percentage, $W_{C N T}$. Circles: experimental data; solid line: theoretical curve (formula (6)).

\section{Conclusions}

Engineering of mechanical properties of epoxy-based multicomponent composite material has been achieved via the addition of single-wall carbon nanotubes (CNTs) at low concentration to the epoxy matrix.

Samples under study demonstrate mechanical enhancement effect due to the strong interaction between CNT guest substance and host epoxy matrix.

\section{ACKNOWLEDGEMENTS}

The authors thank OCSiAL (Novosibirsk, Russia) for 
the support of high-quality CNT.

The authors are grateful to Prof. V. V. Ostashev and Prof. A. I. Vanin for fruitful discussions.

\section{REFERENCES}

[1] C. P. Poole, Jr., F. J. Owens, Introduction to nanotechnology. Wiley-Interscience, 2003.

[2] Yiu-Wing Mai and Zhong-Zhen Yu, Eds., Polymer nanocomposites. Cambridge, England: Woodhead Publishing Limited, 2006.

[3] C. Leopold, T. Augustin, T. Schwebler, J. Lehnann, W. V. Liebig, B. Fiedler, "Influence of carbon nanoparticle modification on the mechanical and electrical properties of epoxy in small volumes", Journal of Colloid and Interface Science, vol. 506, pp. 620-632, 2017.

[4] A. A. Moosa, A. Ramazani, M. N. Ibrahim, "Effects of carbonnanotubes on the mechanical and electrical properties of epoxy nanocomposites", International Journal of Current Engineering and Technology, vol. 5, pp. 3253-3258, 2015.

[5] C. Xiao, Y. Tan, X. Wang, L. Gao, L. Wang, Z. Qi, «Study of interfacial and mechanical improvement of carbon fiber / epoxy composites by depositing multi-walled carbon nanotubes on fibers», Chemical Physics Letters, vol. 703, pp. 8-16, 2018.

[6] G. V. Kozlov, "Structure and properties of particulate-filled polymer nanocomposites", Uspekhi Fizicheskikh Nauk, vol. 185 , pp. 35-64, 2015.
[7] B. Pukanszky, "Influence of interface interaction on the ultimate tensile properties of polymer composites", Composites, vol. 21, pp. 255-262, 1990.

[8] Y. Zare, K. Y. Rhee, "Multistep modeling of Young's modulus in polymer / clay nanocomposites assuming the intercalation / exfoliation of clay layers and the interphase between polymer matrix and nanoparticles", Composites: Part A, vol. 102, pp.137-144, 2017.

[9] A. Kelley, G. J. Davies, "The principles of the fibre reinforcement of metals", Metallurgical Reviews, vol. 10, pp. 1-77, 1965.

[10]A. Kelly, W. R. Tyson, "Tensile properties of fibre-reinforced metals: Copper / tungsten and copper / molybdenum", Journal of the Mechanics and Physics of Solids, vol. 13, pp. 329-350, 1965.

[11] Y. Zare, "Effects of interphase on tensile strength of polymer / CNT nanocomposites by Kelly-Tyson theory", Mechanics of Materials, vol. 85, pp. 1-6, 2015.

[12] V. Lutz, J. Duchet-Rumeau, N. Godin, F. Smail, F. Lortie, J. F. Gerard, "Ex-PAN carbon fibers vs carbon nanotubes fibers: From conventional epoxy based composites to multiscale composites", European Polymer Journal, vol. 106, pp. 9-18, 2018.

[13]A. K. Mikitaev, G. V. Kozlov, «The structural model of strength of nanocomposites poly(methyl methacrylate) / functionalized carbon nanotubes», Materials Physics and Mechanics, vol. 24, pp. 187-193, 2015.

[14]A. Mikitaev, G. Kozlov, G. Zaikov, Polymer Nanocomposites: Variety of Structural Forms and Applications. New York: Nova Science Publishers, 2008. 